\title{
Uncertainty in Carbon Capture and Storage (CCS) deployment projections: a cross-model comparison exercise
}

\author{
Barbara Sophia Koelbl • Machteld A. van den Broek • \\ André P. C. Faaij • Detlef P. van Vuuren
}

Received: 18 July 2013 / Accepted: 23 December 2013 /Published online: 27 February 2014

(C) Springer Science+Business Media Dordrecht 2014

\begin{abstract}
Carbon Capture and Storage (CCS) can be a valuable $\mathrm{CO}_{2}$ mitigation option, but what role CCS will play in the future is uncertain. In this paper we analyze the results of different integrated assessment models (IAMs) taking part in the 27th round of the Energy Modeling Forum (EMF) with respect to the role of CCS in long term mitigation scenarios. Specifically we look into the use of CCS as a function of time, mitigation targets, availability of renewables and its use with different fuels. Furthermore, we explore the possibility to relate model results to general and CCS specific model assumptions. The results show a wide range of cumulative capture in the 2010-2100 period (600-3050 $\mathrm{GtCO}_{2}$ ), but the fact that no model projects less than $600 \mathrm{GtCO}_{2}$ indicates that CCS is considered to be important by all these models. Interestingly, CCS storage rates are often projected to be still increasing in the second half of this century. Depending on the scenario, at least six out of eight, up to all models show higher storage rates in 2100 than in 2050. CCS shares in cumulative primary energy use are in most models increasing with the stringency of the target or under conservative availability of renewables. The strong variations of CCS deployment projection rates could not be related to the reported differences in the assumptions of the models by means of a cross-model comparison in this sample.
\end{abstract}

\section{Introduction}

CCS is often mentioned as a key response option to mitigate greenhouse gas emissions (Fisher et al. 2007). The technology can be used to reduce emissions from power plants, hydrogen

This article is part of the Special Issue on "The EMF27 Study on Global Technology and Climate Policy Strategies” edited by John Weyant, Elmar Kriegler, Geoffrey Blanford, Volker Krey, Jae Edmonds, Keywan Riahi, Richard Richels, and Massimo Tavoni.

Electronic supplementary material The online version of this article (doi:10.1007/s10584-013-1050-7) contains supplementary material, which is available to authorized users.

B. S. Koelbl $(\bowtie) \cdot$ M. A. van den Broek • A. P. C. Faaij • D. P. van Vuuren

Copernicus Institute of Sustainable Development, Utrecht University, Heidelberglaan 2, 3584 CD Utrecht, The Netherlands

e-mail: b.s.koelbl@uu.nl

D. P. van Vuuren

PBL Netherlands Environmental Assessment Agency, PO Box 303, 3720 AH Bilthoven, The Netherlands 
production, and industrial facilities and thus forms an alternative to renewables, nuclear power, and bio-energy (without CCS). The strength of CCS compared to some of these options is that relatively little system changes are required. Moreover, costs to reach different climate targets are often projected to be lower if CCS is part of the mitigation portfolio (Azar et al. 2006; IEA 2012; IPCC 2005). Furthermore, CCS can be very important to substantially reduce carbon emissions in some of the most $\mathrm{CO}_{2}$ intensive industries (steel, cement, etc.) (IEA 2012). Finally, bioenergy with CCS (BECCS) can create negative emissions, allowing to reach even ambitious climate goals (Azar et al. 2010).

However, the technology is still surrounded by uncertainties and questions: 1) integrated CCS systems ${ }^{1}$ are barely used on a large-scale (IEA 2012) such that costs and technical challenges are difficult to foresee (Flannery 2011). 2) Storage capacity estimates are uncertain and vary (Bradshaw et al. 2007; GEA 2012; IPCC 2005). 3) CCS may bear risks with respect to leakage (GEA 2012; IPCC 2005), 4) CCS is afflicted with various concerns from the public sphere (GEA 2012), and finally 5) in combination with fossil fuels, the energy system would still rely on non-renewable energy sources. Presumably related to some of these issues, CCS is often mentioned as a "bridging technology" to "buy time" (see e.g. (Bauer 2006; Praetorius and Schumacher 2009; EU 2009)) easing the transition to a renewable-based system (Bauer 2006; Praetorius and Schumacher 2009), while still reducing emissions.

The future role of CCS in the energy system is uncertain. Deployment projections by integrated assessment models (IAMs) can be used to explore the future role of the technologies, based on different assumptions about technology development, climate policy and many other variables. Model comparison studies, like undertaken by the Energy Modeling Forum (EMF), have proven to be an effective tool to explore uncertainties of technologies and the implications for mitigation strategies in different models and to achieve a certain degree of robustness of conclusions (see overview EMF19 Weyant (2004)). So far relatively little explicit attention was paid to different CCS deployment strategies in such studies. A partial exception is the comparison of CCS deployment of the IPCC TAR-scenarios ${ }^{2}$ as summarized in the IPCC (2005), but this study included only three models explicitly representing CCS and provided little detail. Still, from individual model studies of the EMF19 interesting conclusions regarding the importance, and uncertainty or sensitivity to techno-economic assumptions of CCS can be drawn (e.g. (Akimoto et al. 2004; Kurosawa 2004; Riahi et al. 2004; SmekensRamirez Morales 2004)). The model comparison study EMF27, a consortium of 18 IAMs, pays specific attention to the role of different technologies such as bio-energy and renewables in mitigation strategies (Rose et al. 2013; Luderer et al. 2013). Using the data from this EMF round, the present study is looking into the role of CCS.

What role CCS can play, under which circumstances, and how this is influenced by model assumptions and type, is important to find out for policy makers and modelers. Using the EMF27 outcomes, in this paper we look into the following questions: What is the role of CCS in the different models in this century? How strong is the variation across the model results? Which influence do the mitigation target and the assumptions about renewables have? Is there enough storage capacity available? Which primary energy fuels are applied with CCS in the energy system over time and, in particular, in cumulative electricity production? How is this altered by the target and pessimistic assumptions for renewables? Finally, we try to relate the

\footnotetext{
${ }^{1}$ Globally, only about 17 large-scale integrated projects (i.e. covering the whole chain) under construction or in service have been identified by GCCSI (2013) as of January 2013.

${ }^{2}$ An overview can be found in Morita et al. 2000 as cited in (IPCC 2005).
} 
specific model outcomes to model assumptions and model type. The structure of the paper is organized around the questions formulated above.

\section{Method}

In this paper we use a large set of scenarios from the EMF27 model comparison study, to look specifically into CCS deployment. Below, we briefly discuss the methodology.

An overview of the EMF27 scenarios is provided by Kriegler et al. (2013) and specifically for the technology focus by Krey et al. (2013). All models run scenarios with and without greenhouse gas stabilization targets in combination with different technology assumptions. We only use model runs that project until 2100 and report $\mathrm{CO}_{2}$ captured (i.e. 12 models). Furthermore, we focus on four scenarios:

- The default technology scenarios (Benchmark-Tech) in combination with greenhouse gas concentration targets of 450 and 550 ppmv $\mathrm{CO}_{2}$-eq.

- The scenarios with pessimistic assumption about renewables (Low-Renewable) with a greenhouse gas concentration target of 450 and 550 ppmv $\mathrm{CO}_{2}$-eq.

More detailed information about the EMF27 scenarios can be found in Krey et al. (2013), Kriegler et al. (2013) and supplementary material of Kriegler et al. (2013). Assumptions about availability of nuclear and CCS, as well as energy intensity development are the same in the four scenarios. Benchmark-Tech scenarios further assume high technological progress of wind and solar as well as optimistic (but sustainable) biomass potentials. In contrast, the Low-Renewable cases assume conservative technological progress of renewables and limit bioenergy potentials to $100 \mathrm{EJ} / \mathrm{yr}$. The carbon price in the four scenarios ranges between the models from 96 to 852 (BenchmnarkTech-450), 174-2000 (Low-Renewable-450), 35-449 (Benchmark-Tech-550), and 85550 (Low-Renewable-550) $\mathrm{USD}_{2005} / \mathrm{tCO}_{2}$ in 2050 and from 204 to 3348 (BenchmnarkTech-450), 1898-20000 (Low-Renewable-450), 92-1188 (Benchmark-Tech-550), and 144-2369 (Low-Renewable-550) $\mathrm{USD}_{2005} / \mathrm{tCO}_{2}$ in 2100.

We selected these scenarios: 1) As CCS is only used in mitigation scenarios, 2) to analyze the dependence of CCS deployment on the stringency of the climate target and 3) to look into competition with other low $\mathrm{CO}_{2}$ emitting options (in particular renewables). For each of these scenarios we look at the development of $\mathrm{CO}_{2}$ storage rates over time and the total variation of cumulative $\mathrm{CO}_{2}$ stored. Then, we compare the change in this amount and the share of CCS in cumulative primary energy used between scenarios. Furthermore, we compare projected cumulative storage until 2100 (and simple extrapolations beyond) to global potential estimates. Subsequently, we investigate the differences in fuels used with CCS between scenarios.

Finally, we try to explore whether the variation in the model outcomes can be related to relevant general and CCS-specific assumptions or model types. For this, we compiled an overview of assumptions regarding the way CCS is modeled in the IAMs by consulting the modeling teams (Tables 1 and 2). Moreover, different model types may have tendencies to undervalue, or overvalue, for example, mitigation costs (IPCC 2005). We test this for the results of $\mathrm{CO}_{2}$ capture projections of these models. Consequently, we classified the models into three different groups on the basis of available model documentation (see supplementary material, Table 1): 1) technology-focus, 2) macro-economic-focus and 3) hybrid models, leaning on distinctions made by Löschel (2002) and Hourcade et al. (2006). 


\section{Results}

\subsection{CCS deployment}

First, results show that CCS plays an essential role in the $\mathrm{CO}_{2}$ mitigation scenarios of all models looked at (Figs. 1 and 2). In fact, the cumulative capture in these models is at minimum about 600 and at maximum about $3000 \mathrm{GtCO}_{2}$ until 2100. The scenario averages across the models are at least around 1160 in the Low-Renewable-450 and at most $1480 \mathrm{GtCO}_{2}$ in the Low-Renewable-550 scenario. The shares of primary energy used with CCS demonstrate also the relative importance of CCS in the models. In 2050 they range from 9 to $53 \%$ and in 2100 from 15 to $70 \%$. Across the 42 model runs the average shares are $30 \%$ in 2050 and $41 \%$ in 2100. In electricity production, the average shares are $37 \%$ in 2050 and $34 \%$ in 2100 .

Second, Fig. 1 also shows that the majority of the models in all four scenarios have higher storage rates in 2100 than in 2050 (Tables 8 and 9 in supplementary material). This is an interesting result because CCS is often mentioned as a "bridging technology" to "buy time" (Bauer 2006; Praetorius and Schumacher 2009; EU 2009). Apparently, CCS remains competitive throughout the 21 st century. Obviously, in the longer time frame physical limits to storage imply that the technology will need to be substituted by other energy forms. Still, the role of CCS as a key contributor to energy supply during the 21 st century instead of a bridging technology will possibly have consequences for technology pathways in various regions.

A third observation is that there is clearly a wide divergence across models about the capture rate over time and total projected $\mathrm{CO}_{2}$ capture. For instance, by the end of the century, GRAPE projects the highest value of about $64 \mathrm{GtCO}_{2} / \mathrm{yr}$, while WITCH projects $12 \mathrm{GtCO}_{2} / \mathrm{yr}$ in the Low-Renewable-550 (the overall range is $8-64 \mathrm{GtCO}_{2} / \mathrm{yr}$ ). Not surprisingly, the calculations of cumulative $\mathrm{CO}_{2}$ captured also differ widely, ranging from 625 (BET) to $2449 \mathrm{GtCO}_{2}$ (IMACLIM) within the $450 \mathrm{ppmv}$ scenarios. For the $550 \mathrm{ppmv}$ target, the cumulative capture ranges from 613 (WITCH) to $3061 \mathrm{GtCO}_{2}$ (GRAPE).

\subsubsection{CCS deployment differences between scenarios}

Interestingly, Fig. 1 suggests that the overall storage is higher under the less stringent target. It should be noted however, that some models are included in the $550 \mathrm{ppmv}$ and not in the $450 \mathrm{ppmv}$ scenarios. Comparing only the models included in both runs, shows that under the BenchmarkTech assumptions the tight majority of models (six out of ten models (6/10)) project higher storage rates in 2050 as well as higher cumulative capture (2010-2100) when the target is more stringent. (Note: the differences are often small. Four out of ten models show a difference less than $\pm 1 \mathrm{Gt} / \mathrm{yr}$, similarly for cumulative values). ${ }^{3}$ In the Low-Renewable scenarios, half of the models $(4 / 8)$ project lower 2050-storage rates and lower cumulative $\mathrm{CO}_{2}$ capture in the 450 ppmv than in the 550 ppmv scenario (again, often small differences). Furthermore, it is not generally the case that pessimistic assumptions about renewables come with higher storage activity. Under the $450 \mathrm{ppmv}$ target the storage rate in 2050 as well as the cumulative $\mathrm{CO}_{2}$ captured is often higher (4/8 and 6/8 models, respectively) in the Benchmark-Tech than in the Low-Renewable case. Under the 550 target, in contrast, this is in most cases higher in the Low-Renewable case: 10 of 12 models have higher 2050-storage rates and 9 of 12 also higher cumulative capture. Again, often differences are small, but average values confirm this tendency.

Finally, looking at CCS shares in cumulative primary energy provides a more insightful figure than cumulative $\mathrm{CO}_{2}$ capture values alone: $\mathrm{CCS}$ shares in cumulative primary energy

\footnotetext{
$\overline{{ }^{3} \text { Precise differences are in Table } 2}-5$ supplementary material.
} 


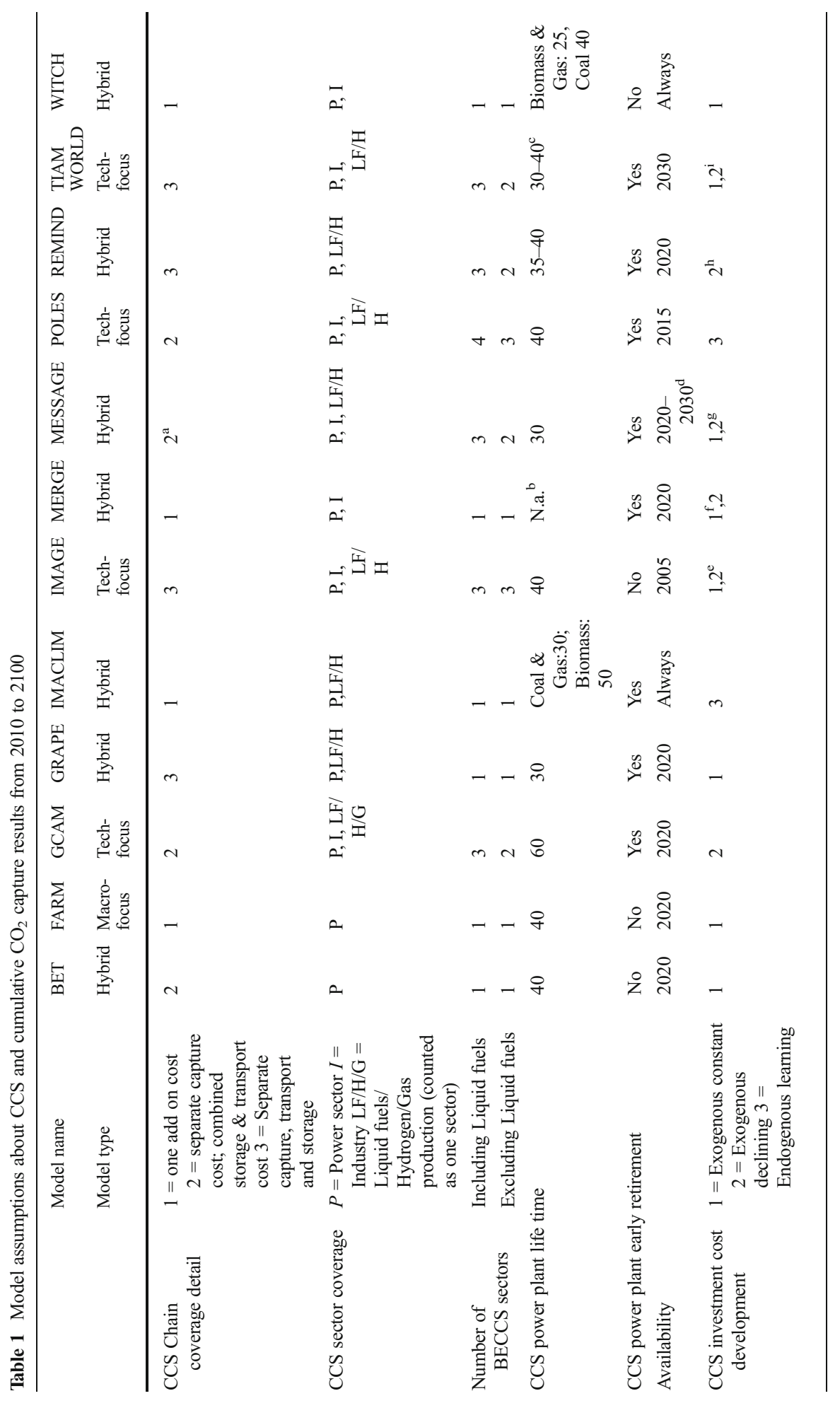




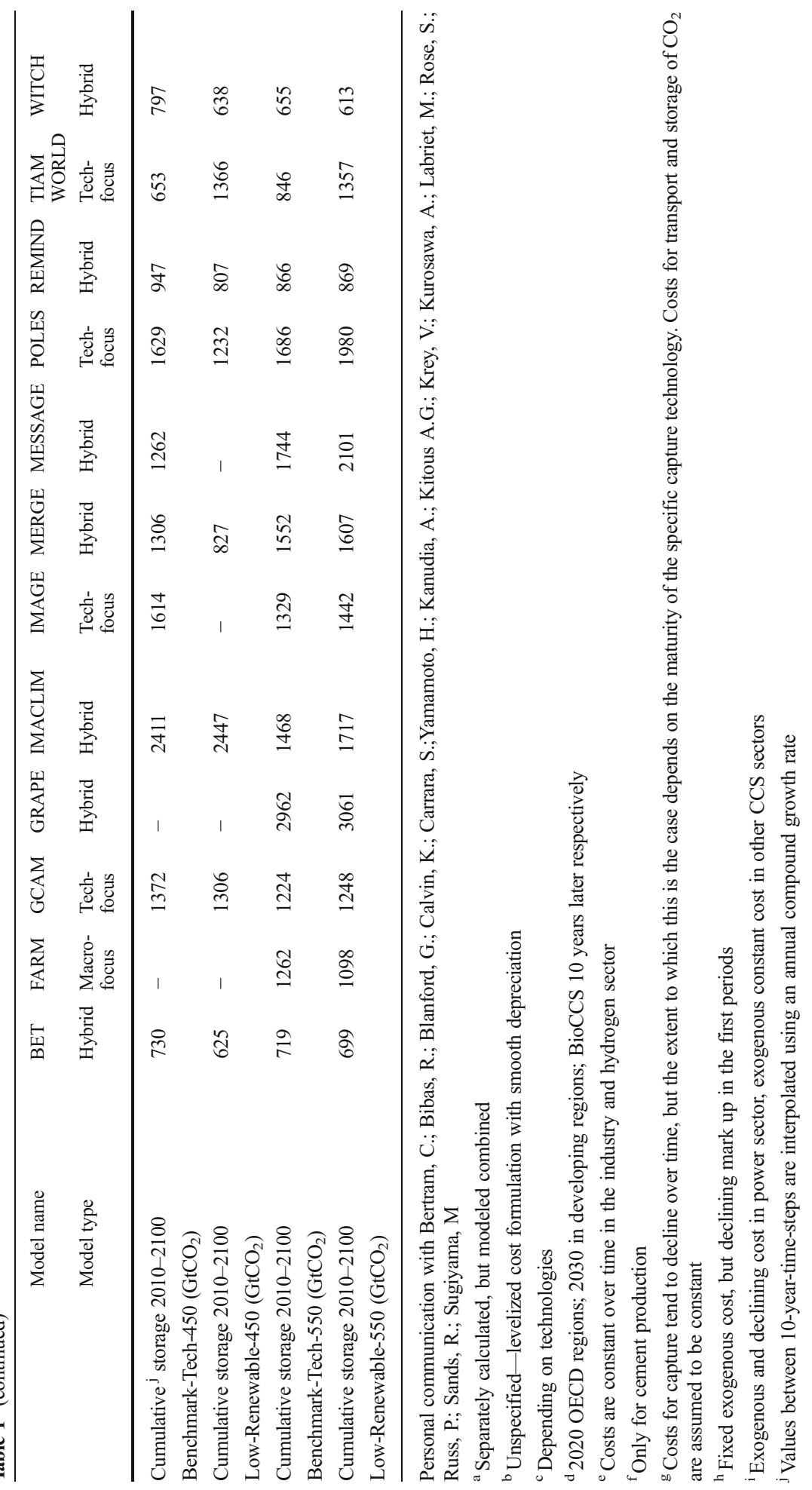




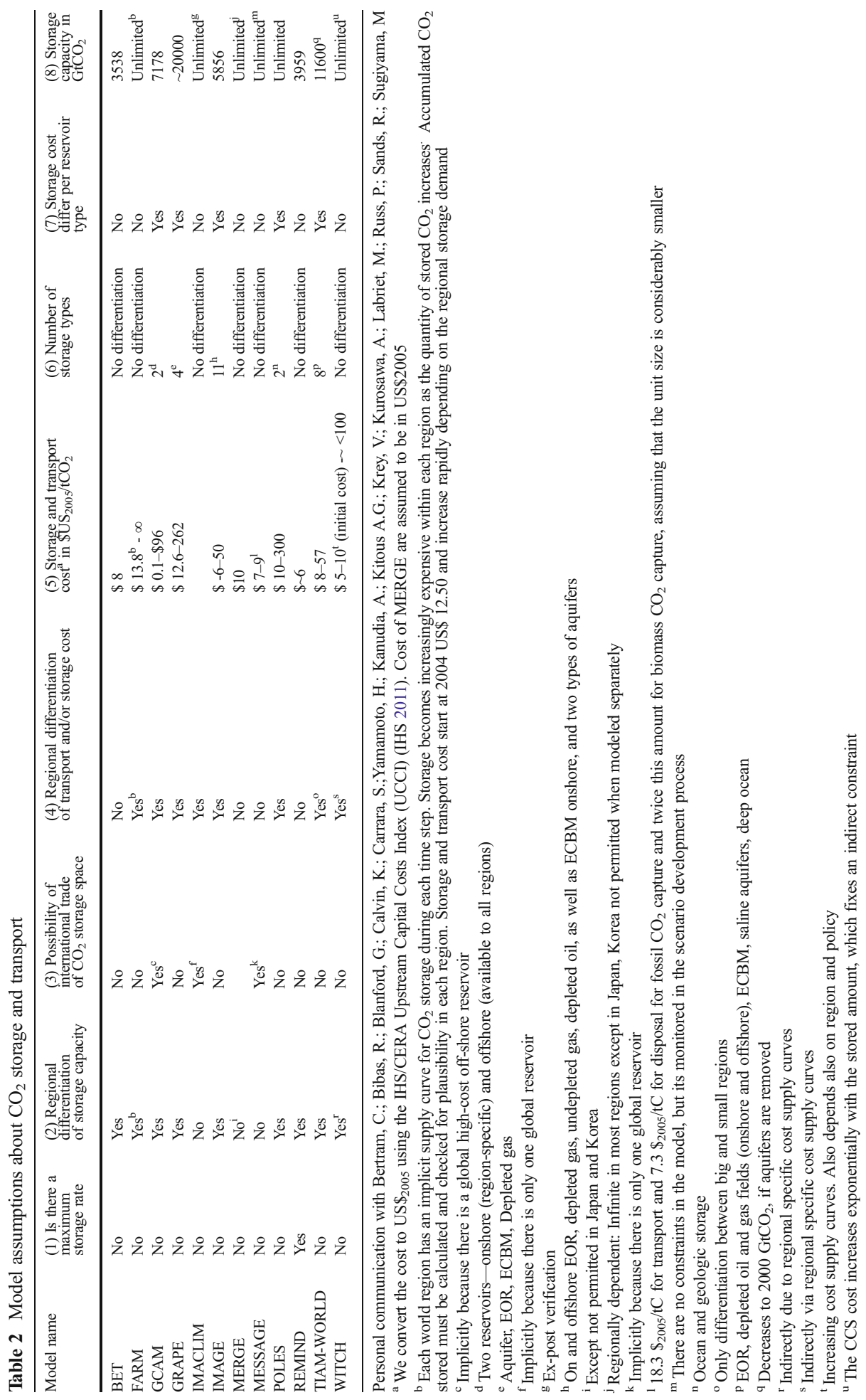


use are somewhat higher for the stringent targets (8/10 and 6/8 models under Benchmark and Low-Renewable conditions, respectively). As one would expect, pessimistic assumptions about renewables usually lead to higher CCS shares in 2050 (8/8 and 12/12 models under 450 and 550 ppmv, respectively), and higher cumulative energy use (7/8 and 12/12 models under 450 and 550 ppmv, respectively). Again, the differences are often small.

\subsubsection{Mechanisms behind CCS deployment differences between scenarios}

An analysis of the change in related variables can help understand why cumulative $\mathrm{CO}_{2}$ capture rates and $\mathrm{CCS}$ shares in primary energy use can be lower in the pessimistic renewable or stringent target scenarios. We can distinguish three groups of models: those with lower cumulative $\mathrm{CO}_{2}$ capture, but higher CCS shares in cumulative primary energy use (group 1), those with lower values for both (group 2) and models that project - as expected-higher values for both (group 3). In Table 6 and 7 in the supplementary material we try to explain the behavior of these groups by looking at the changes in cumulative primary energy use, the cumulative primary energy use with CCS, and the carbon intensity of the fuel mix used with CCS technologies.

In models of the first two groups, cumulative primary energy use decreases as a result of the increased carbon price. Consequently, cumulative primary energy used with CCS often decreases as well. ${ }^{4}$ In models of group 1 , the percentage decrease of total cumulative primary energy used is stronger than the reduction of cumulative CCS primary energy used. Therefore, CCS shares increase. In contrast, in models of group 2, the cumulative fuel used with CCS decreases faster than the overall cumulative primary energy used and thus the shares of CCS decrease.

Also cumulative $\mathrm{CO}_{2}$ capture decreases because the total amount of primary energy used with CCS decreases in most models of group one and two. Furthermore, it decreases in some models because the fuel mix used for CCS technologies changes to less carbon intensive fuels. Replacement of higher carbon fuels may occur to reduce costs of the remaining emissions as well as storage costs. Both are highest for coal and biomass due to the higher carbon content compared to natural gas and oil.

\subsection{Is there enough storage capacity?}

Most models are very optimistic on the use of CCS, but clearly this can depend on the assumption about available storage capacity. Estimates of storage capacity are diverging and uncertain (Bradshaw et al. 2007; IPCC 2005) especially for saline aquifers, ${ }^{5}$ which make the largest share of the estimates. The model assumptions on storage capacity vary considerably with, in fact, half the models assuming no upper limit (Table 2). Here, we compare the amount of $\mathrm{CO}_{2}$ stored until 2100 with other storage capacity estimates.

The most recently published summaries of storage estimates are from GEA (2012) ${ }^{6}$ and IEA GHG (2011). Their range is comparable while the ends in the GEA (2012) with 5050-

\footnotetext{
${ }^{4}$ In some cases there is even an increase in the amount of primary energy used with CCS, although total primary energy used decreases.

${ }^{5}$ According to Bachu et al. (2007), storage capacity in saline aquifers is more difficult to assess because 1) they are less explored than hydrocarbon reservoirs, 2) aquifers are continuous (p. 436), 3) the mechanisms that determine the capacity are very complicated, and require site-specific data (p. 441).

${ }^{6}$ These estimates are acknowledged not to be exhaustive (GEA 2012).
} 

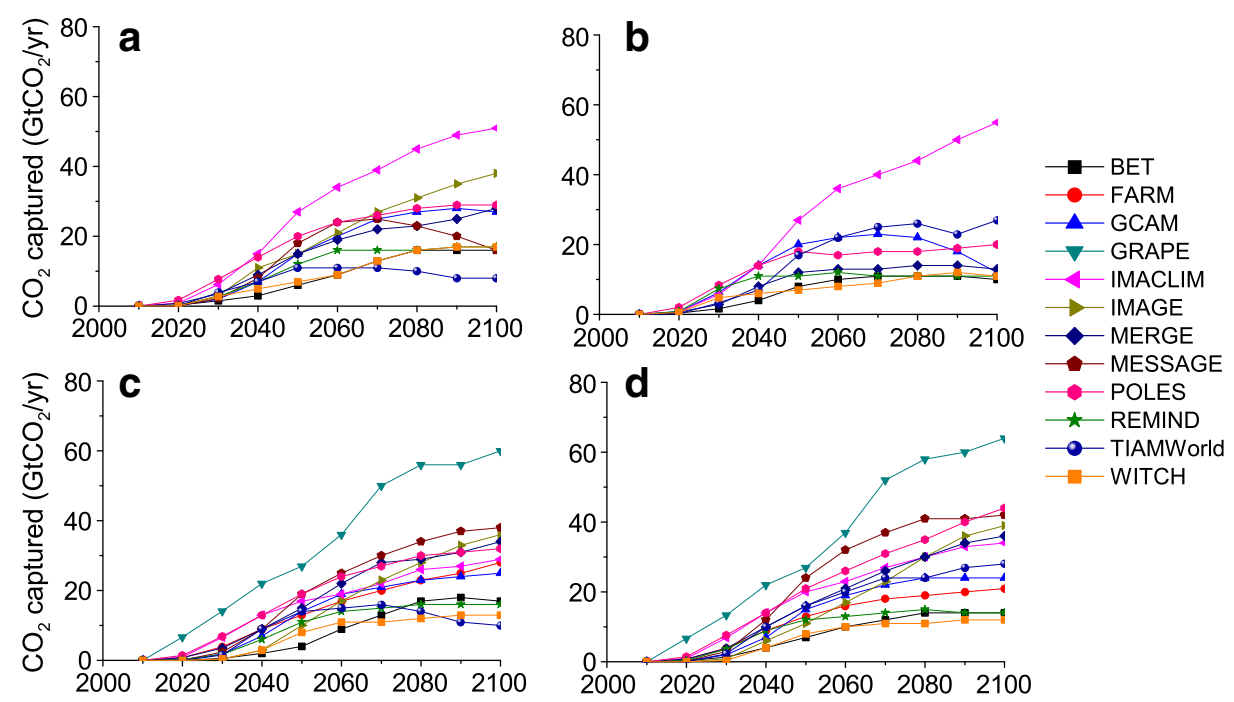

Fig. $1 \mathrm{CO}_{2}$ capture rates until 2100. Benchmark-Tech-450 (a), Low-Renewable-450 (b), Benchmark-Tech-550 (c), and Low-Renewable-550 (d) scenario

$24470 \mathrm{GtCO}_{2}$ are slightly larger than in the IEA GHG (2011) (4890-20950 $\left.\mathrm{GtCO}_{2}\right)$. The respective ranges without aquifers are around 820-3870 Gt (IEA GHG 2011) and around 1090-1300 Gt (GEA 2012). The model results are within these different resource estimates, certainly when aquifers are included. Without them, under the high estimate of IEA GHG
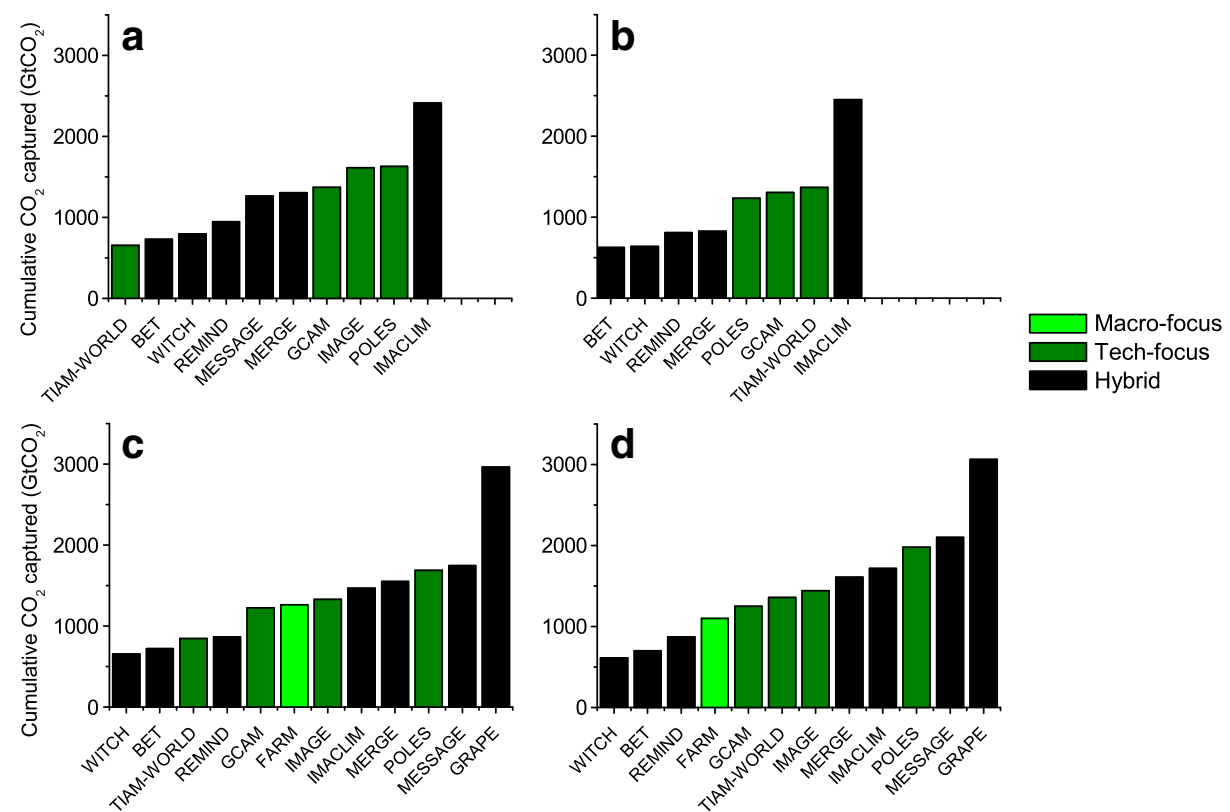

Fig. 2 Cumulative $\mathrm{CO}_{2}$ capture until 2100 per model and model type (values between 10-year-time-steps are interpolated using an annual compound growth rate). Benchmark-Tech-450 (a), Low-Renewable-450 (b), Benchmark-Tech-550 (c), and Low-Renewable-550 (d) scenario 
(2011), enough storage capacity is available at a global level until 2100 for all model runs. However, pessimistic numbers from IEA GHG (2011) and GEA (2012) estimates without aquifers would be exceeded in around $65-75 \%$ of model runs of the current scenarios.

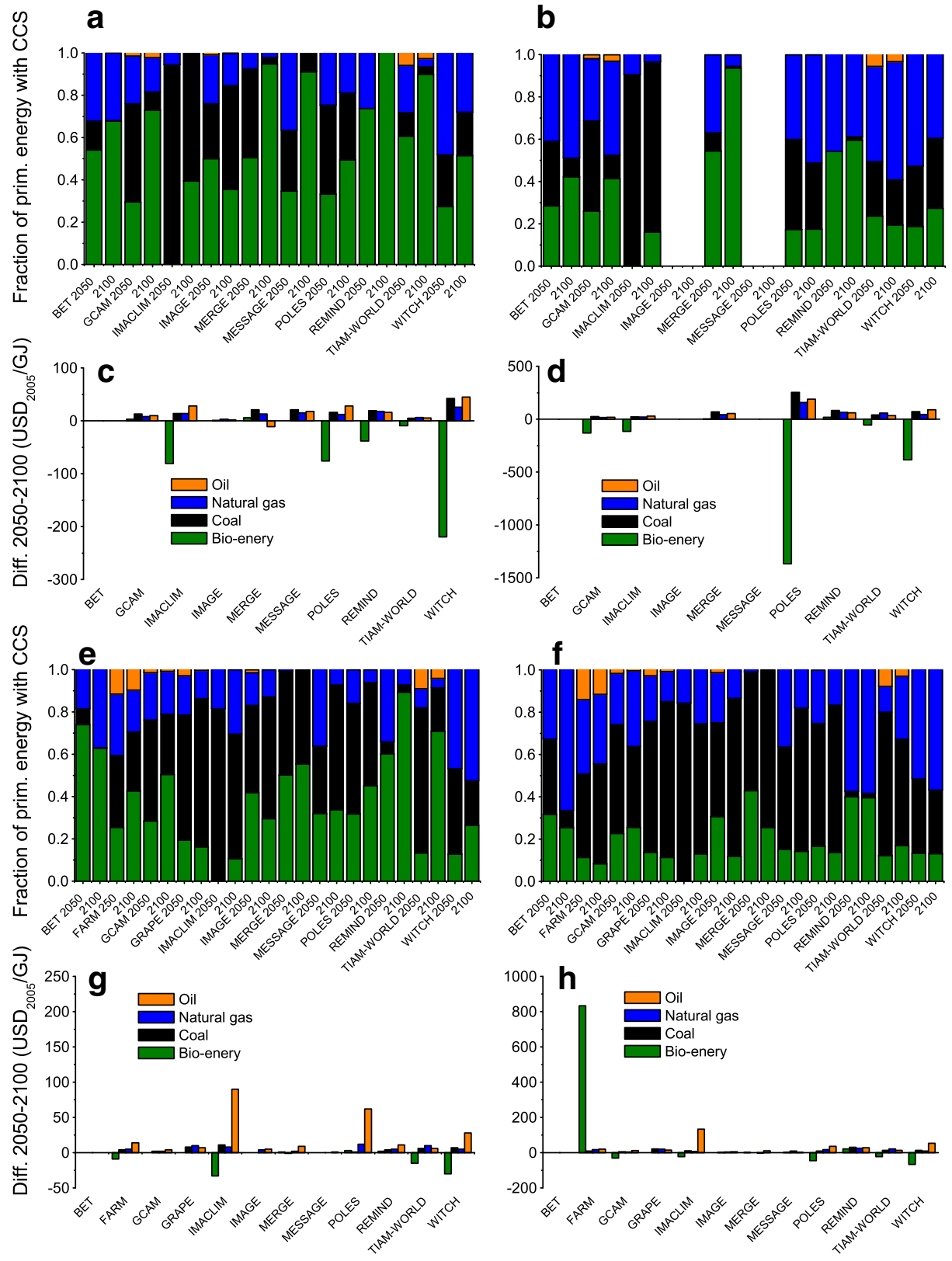

Fig. 3 Share of energy carriers in primary energy used with CCS in 2050 and 2100 and change in price of primary energy between 2050 and 2100 . $\mathbf{a}, \mathbf{b}$, and $\mathbf{e}, \mathbf{f}$, show the share of each energy carrier in total primary energy used with CCS in 2050 and 2100 in the Benchmark-Tech-450 (a), Low-Renewable-450 (b), BenchmarkTech-550 (e) and the Low-Renewable-550 (f). c, d, and $\mathbf{g}, \mathbf{h}$, show the price change in the fuels from 2050 to 2100 including the carbon price for the corresponding scenarios (Note that the scale differs) 
Obviously, given the storage rates in 2100, it is important to realize that also storage would be required after. To see for how long the capacity could last, we assume for simplicity constant storage rates after 2100 . Using pessimistic estimates including aquifers $\left(4890 \mathrm{GtCO}_{2}\right)$, the first model exceeds this estimate before 2130 . About 30 years into the 23rd century half the model runs exceed this estimate as well. Using optimistic numbers without aquifers from the IEA GHG (2011) (3870 $\mathrm{GtCO}_{2}$ ) would still give similar results. The first model run exceeds this capacity in 2113, while it takes almost 80 years extra until half of the model runs hit the limit. However, the optimistic estimates excluding aquifers from the GEA (2012) (1,300 $\mathrm{GtCO}_{2}$ ) are already exhausted by half the models around 2100 .

\subsection{Fuel shares in CCS deployment}

Figure 3 illustrates fuel shares in total primary energy use with CCS over time (2050 and $2100)$. In the Benchmark-Tech-450, most of the models (9/10) substitute away from either coal, natural gas, or both, to higher biomass shares (14-56\%-point increase/ on average $28 \%$ points). This fuel-switching towards biomass is less pronounced in combination with pessimistic assumptions about future renewable energy (average $+12 \%$-points) - in particular bioenergy potentials - and for less stringent emissions mitigation targets (average $+12 \%$ points), or both (average -3\%-points). In the less pessimistic renewable case, the results come from the restriction on bioenergy potentials. For the less ambitious climate target, the result likely comes from the reduced importance of "negative emissions" from BECCS.

Figure 4 shows the share of energy carriers in cumulative CCS electricity generation from 2010 until 2100. The preference of CCS power plants for fuel types varies among the scenarios and models. In the Benchmark-Tech-450 scenario, BECCS has the largest share in the portfolio in 7 of 10 models, whereof five have more than $50 \%$ and the highest is up to $70 \%$. In most models $(5 / 6)$ this changes to natural gas if the scenarios assume low renewable availability (Low-Renewable-450), such that most often (6/8 models) natural gas dominates the cumulative fuel portfolio. Lowering the target (Benchmark-Tech-550) also leads to less dominance of BECCS in CCS electricity. Instead, coal CCS is more often (6/12) dominating in both 550 scenarios. In the Low-Renewable-550, natural gas dominates the portfolio in the other half of the models. (See supplementary material Tables 10-12 for detailed values of this section).

\subsection{Can the model variation be easily explained?}

Several factors could potentially cause the large variation in the model results for CCS as they may have an influence on CCS deployment. This includes 1) fuel prices, 2) baseline emissions, 3 ) the type of model, 4) modeling technology change, and 5) the way CCS is modeled. We test whether such factors - in isolation - can explain the range of model results. In summary, the results show no clear relationships between these factors and the projected $\mathrm{CO}_{2}$ captured of the models. (Section 4 of supplementary martial and Tables 13 and 14 explain and motivate the investigation in detail).

The model results cannot be related to the type of model (Fig. 2). Results of the hybrid models, for example, can be found over the whole range of reported outcomes. Furthermore, Fig. 5 shows that a relationship between capture and the baseline emissions is not apparent from the current data set. Figure 3 shows the fuel shares in primary energy use with CCS for 2050 and 2100 along with the price change of primary energy (the price includes the carbon tax calculated 


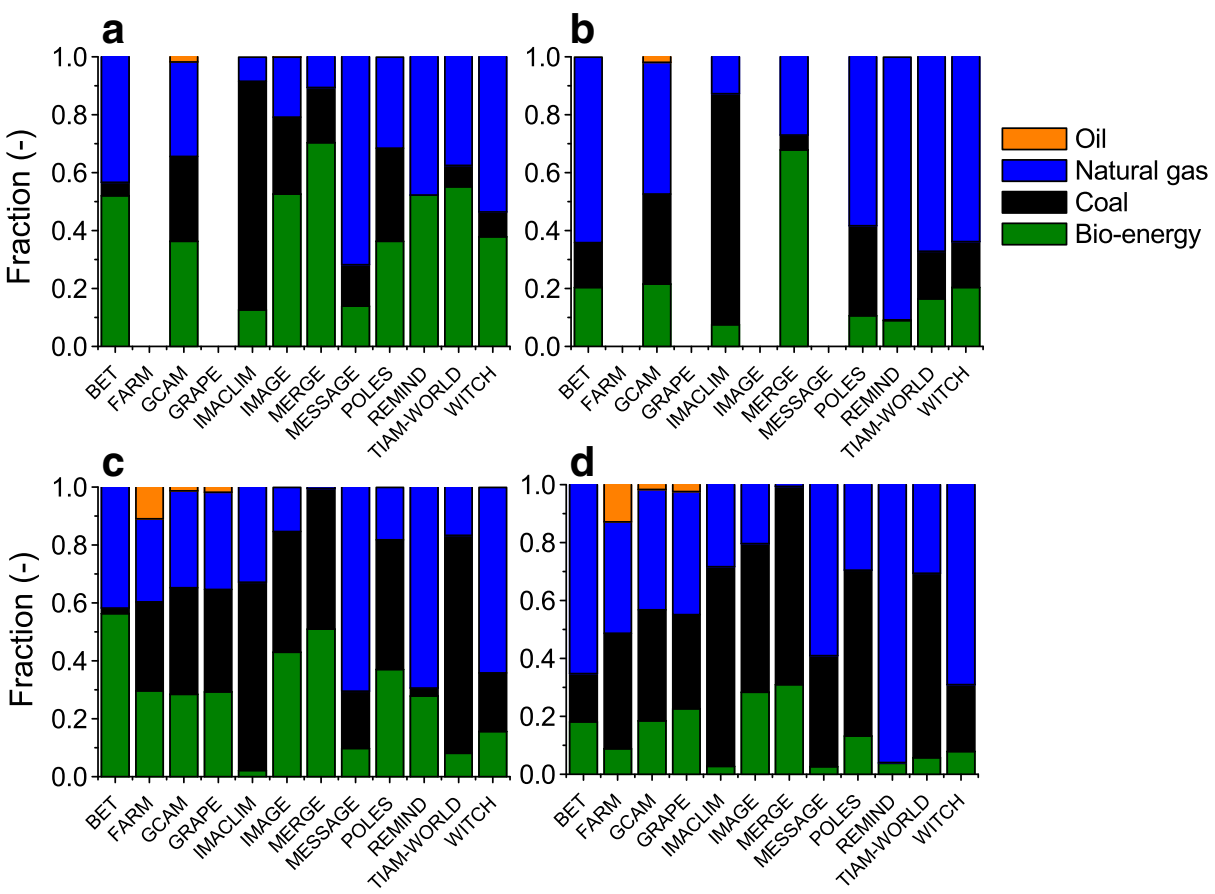

Fig. 4 Share of energy carriers in cumulative electricity production with CCS (2010-2100) (values between 10year-time-steps are interpolated using an annual compound growth rate). Benchmark-Tech-450 (a), LowRenewable-450 (b), Benchmark-Tech-550 (c), and Low-Renewable-550 (d) scenario

based on the estimated carbon price in the models $)^{7}$. A clear relationship between the fuel price increase/decrease and the substitution of shares is not always present for all fuels in all the scenarios and models.

None of the model assumptions (Table 1) about the detail of CCS in the model, sectoral coverage, amount of sectors where BECCS is possible, power plant assumptions or implementation of technological development in the model can be related unambiguously to the amount of $\mathrm{CO}_{2}$ captured cumulatively by the models. Similarly, the model assumptions about $\mathrm{CO}_{2}$ transport and storage as summarized in Table 2 can also not be associated with the model outcomes. Also, no discernible relationship between the storage capacity assumption and the global $\mathrm{CO}_{2}$ stored can be derived (see also Fig. 1 in supplementary material).

Finally, comparing the levelized cost of electricity $(\mathrm{LCOE})^{8}$ for the cheapest CCS option divided by the cheapest carbon-free-alternative, ${ }^{9}$ shows that the model with the lowest cost ratio does not have the highest capture rate, or share of CCS in electricity production and vice versa (See Fig. 2 in supplementary material). This implies that even the combined costs for (among others) fuel, operating and maintenance, transport and storage of the CCS power plant cannot explain the variation, when isolated from the remaining model assumptions.

\footnotetext{
${ }^{7}$ In order to include the carbon price in the primary energy price we assume a carbon content of $95.3,56.1,93.5$ and $70.8 \mathrm{kgCO}_{2} / \mathrm{GJ}$ for biomass, natural gas, coal, and oil respectively (de Vries et al. 2001). Furthermore, we assume a capture rate of $85 \%$. For Biomass we assume that $5 \mathrm{kgCO}_{2-\mathrm{eq}} / \mathrm{GJ}$ are indirect emissions of biomass as summarized in van Vliet et al. (2011:256).

${ }^{8} \mathrm{LCOE}$ does not include the carbon price.

${ }^{9}$ This was only tested for Europe for nine models in the Benchmark-Tech-550.
} 


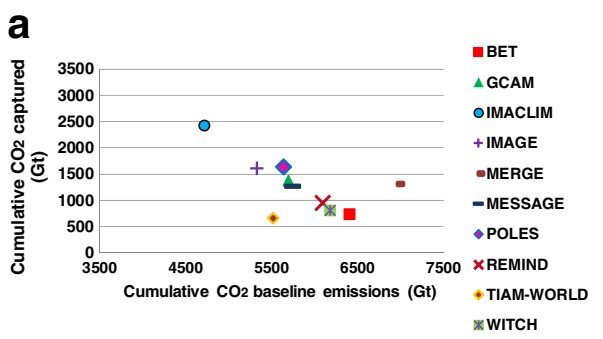

b
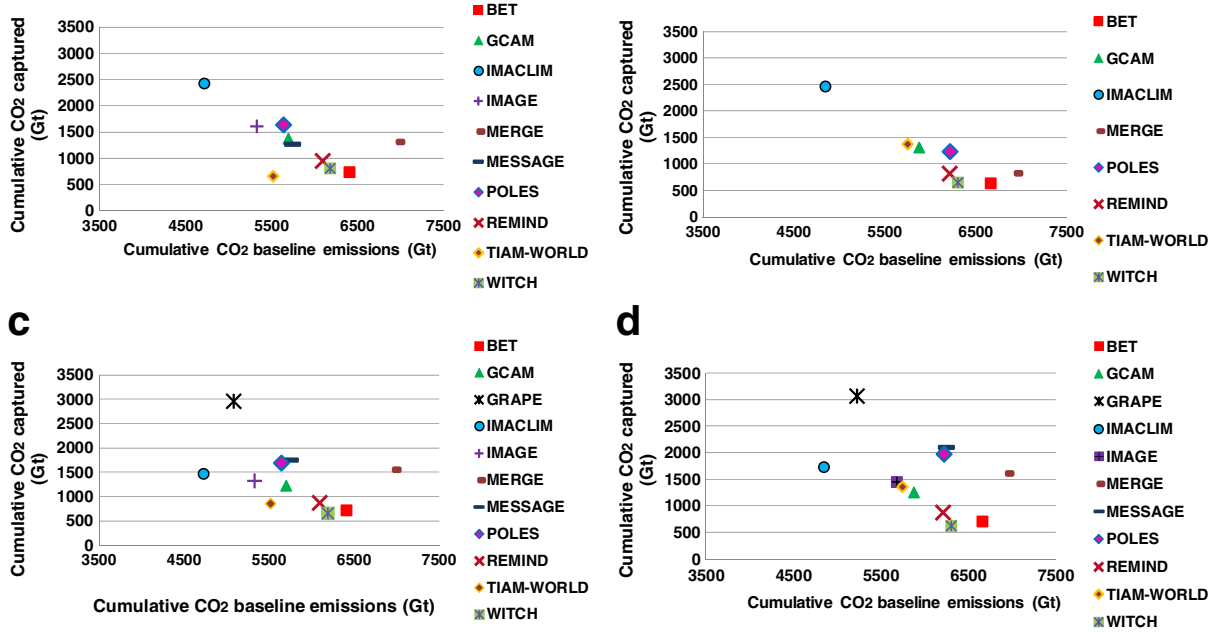

Fig. 5 Cumulative $\mathrm{CO}_{2}$ baseline emissions in relation to cumulative $\mathrm{CO}_{2}$ captured (values between 10-yeartime-steps are interpolated using an annual compound growth rate). Benchmark-Tech-450 (a), Low-Renewalbe450 (b), Benchmark-Tech-550 (c), and Low-Renewable-550 (d) scenario

\section{Discussion}

Although the EMF 27 study included 18 models, only a maximum of 12 models projected values for variables of our interest until 2100. In some scenarios the number of participating models is even smaller (for an overview of the amount of participating models per scenario and models that could not find a solution see Krey et al. (2013)). Therefore, the sample size to derive solid conclusions for the CCS assumption analysis is small. Especially with respect to statistical assessments, conclusions should rather be seen as weak indicators, but not as proofs.

Furthermore, many of the conclusions drawn with respect to the scenario comparison and development of CCS should be interpreted as a tendency found in model results, since they are often based on the majority and average values of results. Hence, other outcomes are possible. Moreover, the conclusion that CCS is more important in model results than suggested by many papers and current investment rates needs to be taken with care. First of all, the model results focus on 2050, i.e. 40 years from now. Second, the models do not include many limitations that are important in reality, like social and political dynamics, or other market barriers (see also IPCC 2005:349,351). Still, the model results suggest that CCS is attractive also in the second half of the century.

Also, we use the amount of $\mathrm{CO}_{2}$ captured as an indication of CCS deployment which is not a precise measure as natural gas and coal have different carbon contents. However, to summarize different sectors, $\mathrm{CO}_{2}$ capture is the most suitable indicator. To confirm results, we also often use the share of CCS in the use of primary energy.

We showed that CCS might be deployed beyond the 21 st century even under pessimistic capacity estimates with aquifers or the optimistic estimate without aquifers from IEA GHG (2011). However, we only compared the global amount of capacity. This does not take into account that the regional distribution of capacity might pose further limitations, i.e. reservoirs could be too far away for some relevant regions. Therefore, a regionally detailed model analysis of this limitation is necessary. 
The classification of model types into three categories is a rather crude exercise. Therefore, the classification of the models can be subject to discussion. However, we have considered different categorizations for some models, (GCAM \& MERGE), which did not change the conclusion.

Confounding effects of variables may exist, including many variables not considered in our comparison (e.g. performance of competing technologies). This is likely an important reason for not being able to explain the CCS outcomes based on model characteristics although impacts seem logical. One key factor not included in our comparison is investment costs. Unfortunately, this data was not sufficiently available. Therefore, we focus on the LCOE of the cheapest CCS option versus the cheapest carbon-free-alternative for nine models of one scenario. Although capital costs usually make a large share in LCOE, no relationship with $\mathrm{CO}_{2}$ captured or CCS shares in primary energy use can be discovered. This indicates that capital costs might also not explain the variation in the cross-model comparison when isolated from other assumptions.

Finally, the fact that we cannot identify a relationship between the model characteristics and the outcomes does not imply that higher detail of models is unnecessary. High detail is still necessary to address specific policy questions. As an example, the regionality of storage potential allows to evaluate the role of CCS on a regional level.

\section{Conclusions}

This study compared the results of the EMF27 modeling round with respect to the deployment of carbon capture and storage. The rationale behind this inquiry was: (1) to investigate whether general conclusions about the importance and tendencies of future CCS deployment can be drawn, (2) to explore the possibility of relating the wide diversity in model projections to model assumptions. Key conclusions are:

CCS plays a key role in the mitigation portfolio of all models looked at. In the models between 600 and $3050 \mathrm{GtCO}_{2}$ is captured cumulatively in this century. The share of CCSrelated technologies in primary energy use is also high under the 450 and 550 ppmv target looked at. The average of all 42 model runs is $30 \%$ in 2050 and $41 \%$ in 2100 . This level contrasts with the small amount of experiments with CCS at the moment.

In most models CCS remains important across the century. While CCS is often mentioned as a bridging technology to advanced renewable energy systems, the models often consider CCS to be important until the end of the 21 st century: here, the $\mathrm{CO}_{2}$ capture rates and the CCS share in primary energy use are higher in 2100 than in 2050 in the majority of the model runs.

There is a large range of outcomes across the models. The projections of $\mathrm{CO}_{2}$ captured cumulatively until 2100 by the different models diverges strongly. Even using the same target and some common technology assumptions for all models, the range of values ( $\sim 600-3060 \mathrm{Gt}$ in Low-Renewable-550) is comparable to the range of model averages that was found by the IPCC-TAR-scenario (133-3462 Gt) (IPCC 2005:356) under the same target, but different baselines.

The large variation in results cannot easily be explained on the basis of individual model assumptions. Apparently, CCS use is a result of a complex interplay of several factors in each model. We have explored the possibility to explain the model results on the basis of known model characteristics and assumptions. In nearly all situations, it turned out not to be possible to easily explain model results on the basis of fuel costs, model types, and general or CCS-specific assumptions. These parameters are thus either not the driving forces, or their impact is confounded by 
other forces such that an external examination cannot identify their impact. Understanding the exact impact of different factors can therefore best be explored in a within-model sensitivity analysis.

Assumed and current estimates of storage capacity do not pose a physical limit on the capture for any model on the global level, as long as aquifers are included. Using the whole range of storage options from the capacity estimates summarized in the literature, shows that there is enough storage potential until the end of the century (and for most models beyond 2100) even when pessimistic estimates are used. However, if we use the pessimistic estimates and exclude all potential for aquifers, storage potential estimates are not sufficient for the global $\mathrm{CO}_{2}$ captured until 2100 in about $65-75 \%$ of the 42 model projections.

Models indicate that under pessimistic technological development of renewable energies, CCS will play a larger role in the primary energy portfolio if one attempts to achieve similar climate targets. Scenario comparisons show that cumulative storage rates are often lower in the Low-Renewable-450 than in the Benchmark-Tech-450. Nevertheless, under the $550 \mathrm{ppmv}$ target the majority of models capture more in the Low-Renewable case. Furthermore, the Low-Renewable cases mostly project higher CCS shares in primary energy use than the Benchmark-Tech cases.

Under the 450 ppmv target $\mathrm{CO}_{2}$ captured is not necessarily higher than under the 550 ppmv target, but CCS shares in primary energy tend to be higher in the majority of models. The 2050 storage rates in the 450 scenarios are not always higher than in the $550 \mathrm{ppm}$ scenarios. In the Low-Renewable case, only in half the models capture rates are higher under the 450 than under the $550 \mathrm{ppmv}$ target. These results seem to be at odds with the model-average values reported from the IPCC-TAR-scenarios (IPCC 2005). Still, the shares of CCS in primary energy use generally increase in most models for the more stringent targets. Reasons for the seemingly counterintuitive projections of CCS deployment under low renewable assumptions or more stringent targets can mostly be explained by less absolute primary energy used for CCS, a fuel switch within CCS technologies (less $\mathrm{CO}_{2}$ is captured) as well as substitution between CCS and other energy sources (determines the share of CCS in primary energy use).

BECCS use is especially attractive under stringent targets and no pessimistic restriction on biomass potentials. $90 \%$ of the models substantially increase BECCS use in their CCS fuel portfolio substituting often for coal and, natural gas over time. When targets are less stringent and/or the biomass potentials are restricted in the scenario, the substitution over time is more heterogeneous between models.

Further research to investigate impacts of CCS modeling parameters using within model studies is recommended. Although the sensitivity to some CCS parameters has been shown before (e.g. (Kurosawa 2004)), it was not possible to relate the variation in results to the CCS parameters in the cross-model comparison. Therefore, we recommend further research in within-model studies to investigate the impact of techno-economic uncertainty on the CCS deployment projections. This also implies that assumptions like costs and performance of technologies should be published with each study.

Acknowledgments This research has been carried out in the context of the CATO-2-program. CATO-2 is the Dutch national research program on $\mathrm{CO}_{2}$ Capture and Storage. The program is financially supported by the Dutch government (Ministry of Economic Affairs) and the CATO-2 consortium parties (http://www.co2-cato.nl/). Furthermore, this research was conducted with the support of the Netherlands Environmental Assessment Agency (http://www.pbl.nl/en/). 


\section{References}

Akimoto K, Tomoda T, Fujii Y, Yamaji K (2004) Assessment of global warming mitigation options with integrated assessment model DNE21. Energy Econ. doi:10.1016/j.eneco.2004.04.021

Azar C et al (2010) The feasibility of low $\mathrm{CO}_{2}$ concentration targets and the role of bio-energy with carbon capture and storage (BECCS). Clim Change. doi:10.1007/s10584-010-9832-7

Azar C, Lindgren K, Larson E, Möllersten K (2006) Carbon capture and storage from fossil fuels and biomasscosts and potential role in stabilizing the atmosphere. Clim Change. doi:10.1007/s10584-005-3484-7

Bachu S, et al (2007) CO2 storage capacity estimation: methodology and gaps. I Int J Greenh Gas Control

Bauer NA (2006) Carbon capture and sequestration: an option to buy time? University Potsdam, Dissertation

Bradshaw J, et al (2007) CO2 storage capacity estimation: issues and development of standards. Int J Greenh Gas Control

de Vries BJM, van Vuuren DP, den Elzen MGJ, Janssen MA (2001) The Targets IMage Energy Regional (TIMER) model. RIVM/PBL, Bilthoven

Fisher BS et al (2007) Issues related to mitigation in the long term context. In: Metz B, Davidson OR, Dave R, Meyer LA (eds) Climate change 2007: Mitigation Contribution of Working Group III to the fourth assessment report of the inter-governmental panel on climate change. Cambridge University Press, Cambridge, pp 169-250

Flannery BP (2011) Comment. Energy Econ

GCCSI (2013) The global status of CCS — Update January 2013. The global status of CCS — Update January 2013

GEA (2012) Global energy assessment - toward a sustainable future. International Institute for Applied Systems Analysis, Vienna, Austria and Cambridge University Press, Cambridge, UK and New York, NY, USA

Hourcade J, Jaccard M, Bataille C, Ghersi F (2006) Hybrid modeling: new answers to old challenges introduction to the special issue of the energy journal. Energy $\mathrm{J}$

IEA (2012) Energy technology perspectives 2012: Pathways to a clean energy system. OECD Publishing

IEA GHG (2011) Potential for biomass and carbon dioxide capture and storage 2011/06

IHS (2011) IHS indexes. In: http://www.ihsindexes.com/. Accessed 21 November 2011

IPCC (2005) IPCC special report on carbon dioxide capture and storage. Prepared by Working Group III of the intergovernmental panel on climate change. Cambridge University Press, Cambridge

Krey V, Luderer G, Clarke LE, Kriegler E (2013) Getting from here to there: energy technology transformation pathways in the EMF27 scenarios. Clim Change Accepted

Kriegler E, et al (2013) The role of technology for achieving climate policy objectives: overview of the EMF 27 study on global technology and climate policy strategies. Clim Change. doi:10.1007/s10584-013-0953-7

Kurosawa A (2004) Carbon concentration target and technological choice. Energy Econ doi:10.1016/j.eneco. 2004.04.022

Löschel A (2002) Technological change in economic models of environmental policy: a survey. Ecol Econ. doi: 10.1016/S0921-8009(02)00209-4

Luderer $\mathrm{G}$ et al (2013) The role of renewable energy in climate mitigation: results from the EMF27 scenarios. Clim Change. doi:10.1007/s10584-013-0924-Z

Praetorius B, Schumacher K (2009) Greenhouse gas mitigation in a carbon constrained world: the role of carbon capture and storage. Energy Policy. doi:10.1016/j.enpol.2009.07.018

Riahi K et al (2004) Technological learning for carbon capture and sequestration technologies. Energy Econ. doi: 10.1016/j.eneco.2004.04.024

Rose S, et al (2013) Bioenergy in energy transformation and climate management. Clim Change Accepted

Smekens-Ramirez Morales KEL (2004) Response from a MARKAL technology model to the EMF scenario assumptions. Energy Econ. doi:10.1016/j.eneco.2004.04.032

EU (2009) DIRECTIVE 2009/31/EC OF THE EUROPEAN PARLIAMENT AND OF THE COUNCIL of 23 April 2009 on the geological storage of carbon dioxide and amending Council Directive 85/337/EEC, European Parliament and Council Directives 2000/60/EC, 2001/80/EC, 2004/35/EC, 2006/12/EC, 2008/1/ EC and Regulation (EC) No 1013/2006. Official Journal of the European Union L 140/114

van Vliet OPR, Broek MAVD, Turkenburg WC, Faaij APC (2011) Combining hybrid cars and synthetic fuels with electricity generation and carbon capture and storage. Energy Policy 39:248-268

Weyant JP (2004) Introduction and overview. Energy Econ. doi:10.1016/j.eneco.2004.04.019 